\title{
CONSTRUCTIVE TASKS AS A TOOL OF INVASIVE AND NON-INVASIVE ASSESSMENT OF KNOWLEDGE*
}

\author{
Chukhnov A. S. ${ }^{1}$, lecturer, $\bowtie$ septembreange@gmail.com \\ ${ }^{1}$ Saint Petersburg Electrotechnical University, \\ 5, building 3, st. Professora Popova, 197376, Saint Petersburg, Russia
}

\begin{abstract}
Constructive tasks are very important and appear in every branch of mathematics. This work is devoted to some experiments with constructive tasks held within the education and assessment process.

Firstly, some remote constructive tasks were given to students within a course of Mathematical Logic and Theory of Algorithms. The tasks served only as a support tool and students were not obliged to solve them. Secondly, tasks of the same types were given to elder students which had already passed the course with an additional request to log their intellectual activity while solving the tasks.

The third experiment was held during the written exam. Constructive tasks which were given to the students appeared as "the reverse" to the tasks they had solved during the semester.
\end{abstract}

Keywords: constructive task, distance learning, non-invasive monitoring.

Citation: A. S. Chukhnov, "Constructive Tasks as a Tool of Invasive and Non-invasive Assessment of Knowledge," Computer tools in education, no. 3, pp. 96-104, 2019; doi: 10.32603/2071-2340-2019-3-96-104

\section{INTRODUCTION}

Constructive tasks are very important and appear in every branch of mathematics.

The importance of constructive tasks in mathematical education is shown in [1]. The main object of this book is a learner generated example: while getting acquainted with a new notion students are asked to construct an example themselves to improve their comprehension of a new topic. "Mathematics can be seen as a constructive and, hence, personally creative activity. Not just simple constructivism... Not just radical constructivism... Not just social constructivism... but also mathematical construction in which to learn is to construct objects meeting specified constraints, so that when example spaces are triggered they are complex and confidence-inspiring, with their components richly interconnected, enabling re-construction and fresh construction as appropriate."

Constructive reasoning in mathematical education is also touched upon in some other works, for example [2-4].

In Saint-Petersburg Electrotechnical University we have been, for years, working on distance tools which are used in some contests and also as supportive ones for students within the courses

${ }^{*}$ The work was supported by the Russian Foundation for Basic Research (Project No 18-013-01130). 
of "Discrete Mathematics" and "Mathematical Logic and the Theory of Algorithms". This work is described in previous articles of the author, as well as, in the works of his colleagues [5-7].

Constructive tasks could also be used not only as supportive tool, but also as a tool of assessment of knowledge. This assessment could be either invasive or not, depending on how it affects the educational process.

\section{CONSTRUCTIVE TASKS IN DISTANT TOOLS}

We generally use six types of constructive tasks. Each of them is supported by its own framework that we call a manipulator.

We have logical schemes, Turing machines, finite state machines, regular expressions and graph manipulators and also the "Tarski World" manipulator which supports predicates in calculus tasks.

For example, the Turing machine task could be formulated as "Construct the Turing machine which inverts the initial string written on the memory tape replacing zeroes with units and vice versa”. Using this manipulator the students can add and edit machine commands and experiment with different initial states on the memory tape. By pressing the "play" button the student launches the Turing machine simulator which allows him to see how would his Turing machine work on the current initial state.

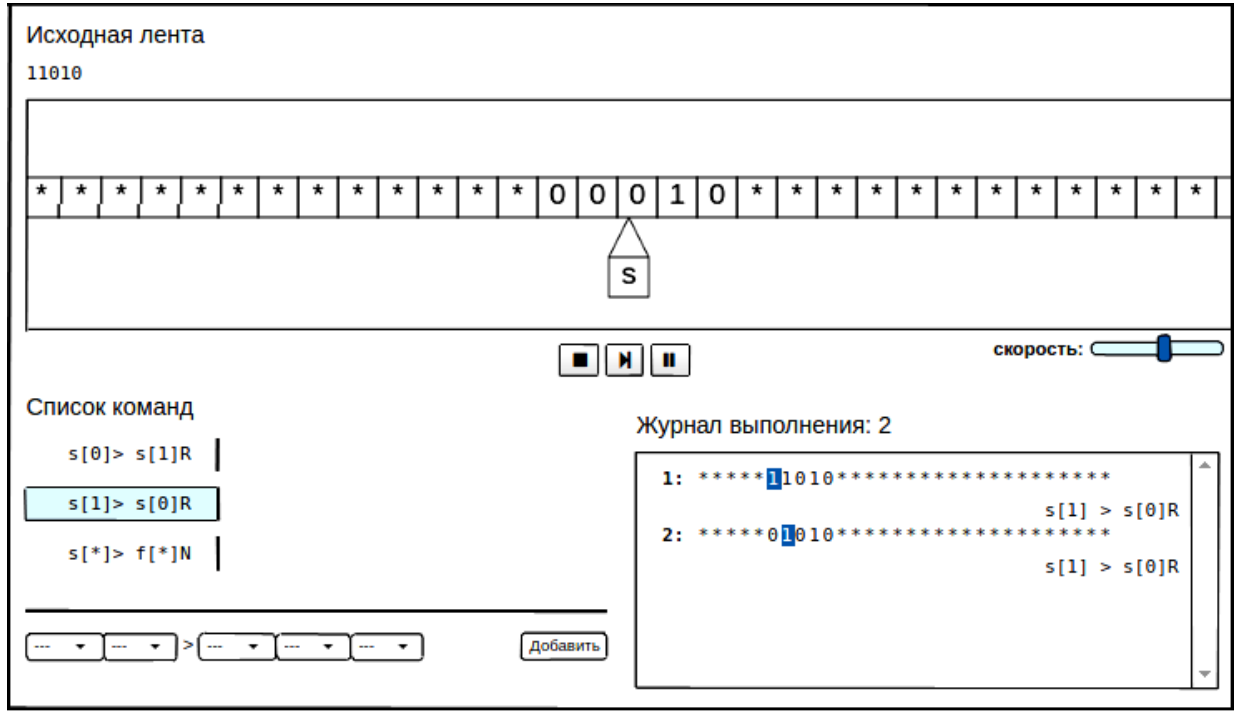

Figure 1. Turing machine manipulator

Those tasks have showed a good effectiveness for students. A survey was held with a question "Your impression of laboratory work before the exam?"

Table 1. Survey results

\begin{tabular}{|l|r|}
\hline Got all answers from other students and quickly finished the work & $6.2 \%$ \\
\hline It was interesting to participate in the Olympiad with a time limit and grading scores & $27.1 \%$ \\
\hline To construct is much more interesting and useful than proving theorems & $45.7 \%$ \\
\hline $\begin{array}{l}\text { Constructive tasks with manipulators allowed me to better understand theoretical } \\
\text { ideas }\end{array}$ & $31.8 \%$ \\
\hline I think that performing these works improved my results on the examination & $14.7 \%$ \\
\hline
\end{tabular}


This tasks could also be used as a tool of non-invasive monitoring.

There is an important question "how can I fairly assess the students knowledge and comprehension"? The obvious answer is "on the exam", but this is not the whole truth. Exam is a necessary but not a best way, just because in the stress situation some students show more than they can, and others show very much less. We may say that sometimes we check not the level of knowledge, but the ability to pass an exam or the level of preparation for a certain test, if questions and tasks are known, more or less, in advance.

This is the reason why we should develop non-invasive tools of assessment of students activity. Non-invasive means that while introducing these tools we don't force the students to prepare to pass certain tests instead of learning the course as a whole.

This goal can be reached by not including our tools in the final assessment. So the only motivation for the student to solve those additional tasks would be the ability to check oneself and to improve one's knowledge.

\section{TRACKING MENTAL ACTIVITY EXPERIMENT}

Construct a finite state machine which recognizes a word in the alphabet $\{0,1\}$ if and only if it doesn't include the subwords 000 and 11111.

This task was given to a group of elder students, which had previously learned this topic two or three years ago. This experiment gave us a huge amount of material which is partly described in this paper.

About $80 \%$ students solved the task correctly although it took hours for some of them just because they needed to recall what is FSM.

All students except one have constructed generally the same FSM. Moreover, most of the FSM constructed were not only isomorphic; actually the corresponding vertices appeared to have the same numbers and also appeared to be located at almost the same places!
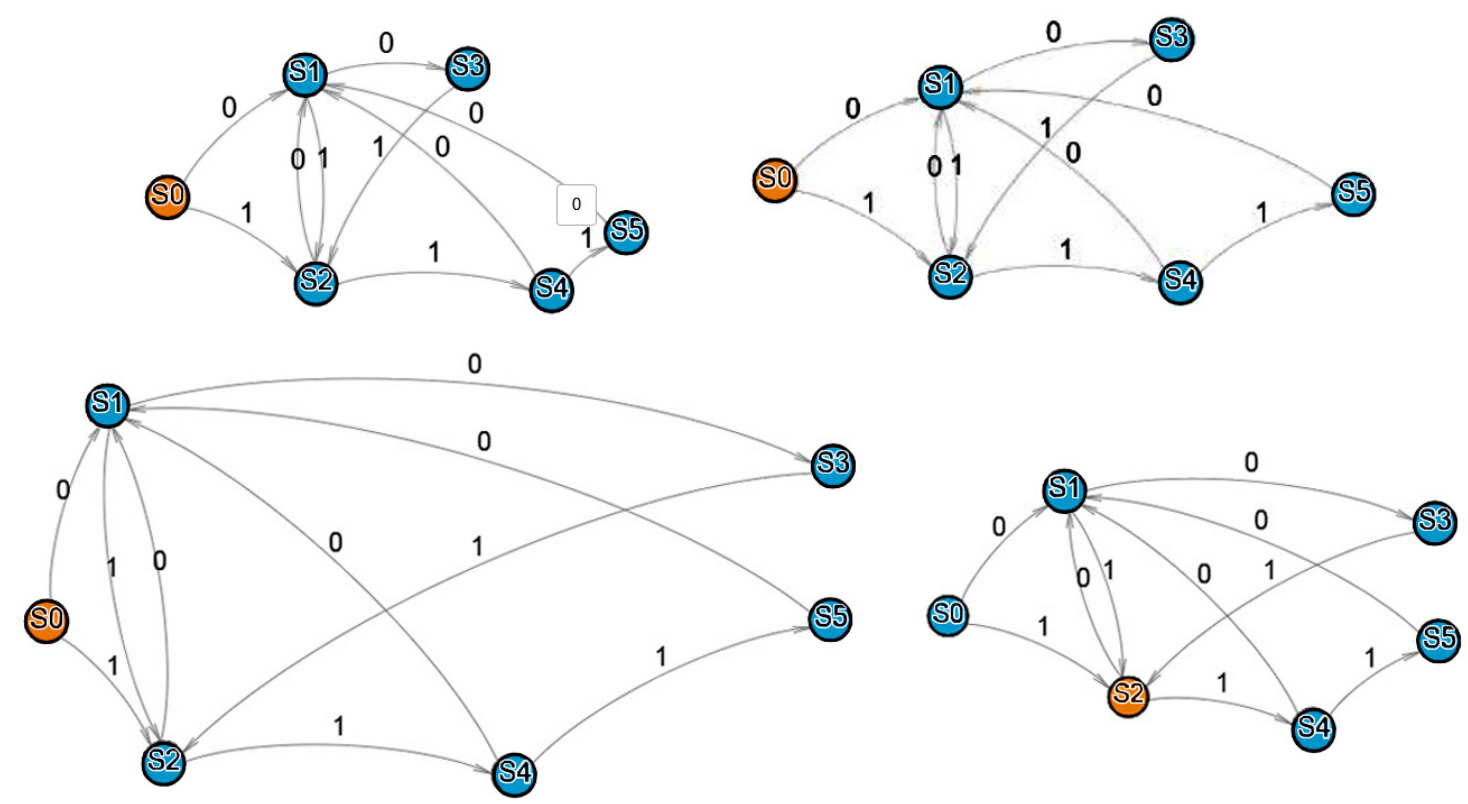

Figure 2. Four different solutions 
How could that happen given that the students didn't cooperate with each other? Firstly, the vertice $S 0$ with links to $S 1$ and $S 2$ were given to the students as the initial solution. The students could move those vertices, but generally had left them as they were.

The next step is to add three more vertices for tracking the numbers of zeroes and units in a row. As we all get used to work from top to bottom and from left to right, there is almost no one way to put and numerate the vertices!
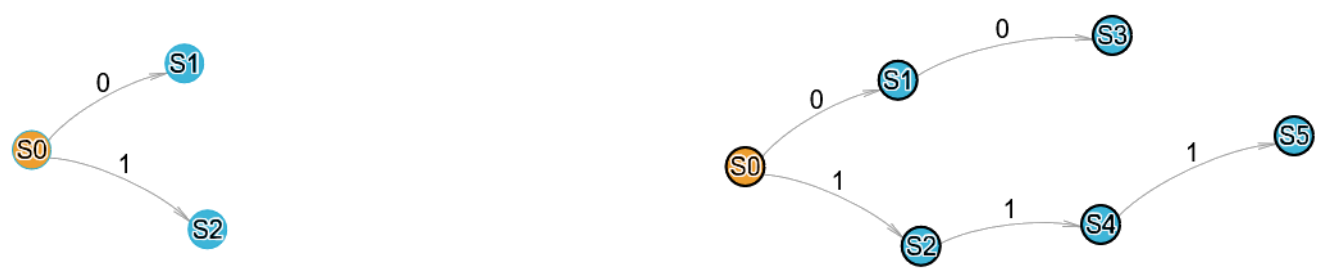

Figure 3. Steps of the solution

What is left to do is to put links between vertices, but we have no choice here at all.

\section{INVERTED TASKS ON EXAM EXPERIMENT}

This year within the course of Discrete Mathematics we held an experiment with constructive tasks. Of course, it couldn't be regarded as a non-invasive monitoring, but it is interesting in itself.

The main idea was to give students the "inverted" versions of the tasks they have solved during the semester.

First task, devoted to letter permutations, was given to 124 students.

This task, as well as, the rest were given to 59 students. They were assessed by the following scale:

Table 2. Marks for the following tasks.

\begin{tabular}{|l|l|}
\hline 1 & Task is solved completely \\
\hline$\frac{2}{3}$ & The solution is generally correct but has some small, for example arithmetical, mistakes \\
\hline$\frac{1}{3}$ & The solution includes some ideas that could be used in the correct solution \\
\hline 0 & The solution is completely incorrect or absent \\
\hline
\end{tabular}

\subsection{Letter permutations}

1. a) How many distinct words we can obtain by letter permutations of the word "SAPRISSA" (including the initial one)?
b) Construct a word ( $\leqslant 20$ letters) with $\frac{7 !}{36}$ permutations.
c) And now, please, construct a word $(\leqslant 20$ letters $)$ with $\frac{7 !}{9}$ permutations.

This is only one example. The words and numbers could differ from student to student, but the concept was always the same.

The first task is a well-known one. It was not included in the tests or individual homeworks, but was solved and analyzed in the classroom. 
The second task is a simple inverted version for the first one. We have a formula with a factorial in the numerator and the number 36 in the denominator which could be easily factorized as $3 ! \cdot 3$ ! which gives us the word like AAABBBC. Of course, we didn't ask the students to find an existing word.

The restriction " $\leqslant 20$ letters" was added just to avoid trivial solution - a word with $\frac{7 !}{36}-1$ letters A and a single letter B.

The third task is generally the same as the second one, but requires a bit more arithmetic: number 9 can't be represented as a nontrivial product of factorials so it is easy to see that we cannot have an answer with 7 letter as in the previous task. But, as $\frac{7 !}{9}=\frac{8 !}{72}$, and $72=2 ! \cdot 3 ! \cdot 3 !$, we have a possible answer like AAABBBCC.

In the table 3 we can see the results of this experiment.

Table 3. Task results

\begin{tabular}{|l|c|c|c|c|c|c|r|}
\hline a) & + & + & + & + & - & - & 117 \\
\hline b) & + & + & - & - & + & - & 117 \\
\hline c) & + & - & - & + & + & - & 97 \\
\hline Number of students & 92 & 20 & 3 & 2 & 3 & 4 & 124 \\
\hline
\end{tabular}

Here we can see that 92 of 124 students (that is about $74 \%$ ) have successfully completed all 3 tasks. Other 20 students have troubles only with the most difficult task. Thus we see that almost all students who knew how to solve initial tasks appeared to be able to solve at least simple inverted ones.

\subsection{Diophantine equations}

1.1. Is it possible to construct a Diophantine equation $a x+b y=c$ with the set of its solution equal to $x=3+16 n, y=5+41 n, n \in \mathbb{Z}$ ? If it is possible, do it.

1.2. For which $f$ and $g$ it is possible to construct a Diophantine equation $a x+b y=c$ with the set of its solution equal to $x=5+f \cdot n, y=11+g \cdot n, n \in \mathbb{Z}$ ?

The task 1.1 is a constructive one, while task 1.2 require more theoretical reasoning. However, both tasks are based on the idea that the set of the following type can be the whole set of a Diophantine equation solutions if and only if $f$ and $g$ are coprime.

Table 4. Task 1 results

\begin{tabular}{|r|r|r|r|r|}
\hline Task No & 1 & $\frac{2}{3}$ & $\frac{1}{3}$ & 0 \\
\hline 1.1. & 12 & 1 & 4 & 42 \\
\hline 1.2. & 1 & 2 & 1 & 54 \\
\hline
\end{tabular}

Here we can see that both task appeared rather hard for the students, especially the theoretical one. 


\subsection{Chinese remainder theorem}

2.1. Represent the number 100 by four of its remainders in the division by four different moduli. No another number in $[1 ; 30000]$ should have the same representation.

Table 5. Task 2 results

\begin{tabular}{|r|r|r|r|r|}
\hline Task No & 1 & $\frac{2}{3}$ & $\frac{1}{3}$ & 0 \\
\hline 2.1. & 6 & 4 & 1 & 48 \\
\hline
\end{tabular}

This task was created as an inversion for Chinese remainder theorem. However, the condition that no modulo should be useless were later removed from this task, so it appeared to be even simpler as actually only a single modulo suffices now.

\subsection{Euler function}

3.1. Does a natural number $n$ such that $\varphi(n)=18$ exist?

3.2. Find all solutions of this equation and prove that there are no other ones.

As is task 1, the first part of this task is a constructive one, and the second part is theoretical.

Table 6. Task 3 results

\begin{tabular}{|r|r|r|r|r|}
\hline Task No & 1 & $\frac{2}{3}$ & $\frac{1}{3}$ & 0 \\
\hline 3.1. & 51 & 0 & 1 & 7 \\
\hline 3.2. & 3 & 5 & 24 & 27 \\
\hline
\end{tabular}

The first part appeared to be quite simple. The second, theoretical part is harder. The mark $\frac{1}{3}$ for this task generally means that the student has found more than one solution for the equation, but completely failed with the proof.

Results which those 59 students have shown on the constructive task 3.1 are much better than they have shown on the other ones. Probably, this can be explained by the fact that, unlike other tasks, on previous exams we very often offered previous students different equations with Euler function.

\subsection{Continued fraction}

4.1. Construct a continued fraction which converges to $\frac{27}{16}$.

Table 7. Task 4 results

\begin{tabular}{|r|r|r|r|r|}
\hline Task No & 1 & $\frac{2}{3}$ & $\frac{1}{3}$ & 0 \\
\hline 4.1. & 7 & 1 & 3 & 48 \\
\hline
\end{tabular}

The difference from task 1.1, 2.1 and 3.1 is that to solve this inverted task here we first need to solve this initial one, that is to find a continued fraction for $\frac{27}{16}$. 


\subsection{Inverted task overall analysis}

At first sight it seems that the results show nothing: the students just solve simple tasks and do not solve complex ones. But then we can see that the percentage of solutions depends not only on the complexity of the inverted task itself, but actually on the complexity of the initial concept as well.

Euler function task, unfortunately, doesn't check the comprehension of the concept of the Euler function: it checks the mastering of Euler function formula which is rather simple.

If we compare this with the task 1.1 concerning Diophantine equation, we may see that solving it requires full understanding of the equation and its solution. But technically it is a very easy task, it may even be easier than finding a number in the preimage of the Euler function: we need to get that $a=41$ and $b=-16$, then submit the required solution into the formula and evaluate $c$.

It is very simple. It is much simpler than the initial task of solving Diophantine equation. But if the solving process of the Diophantine equation is something that student does mechanically, without trying to understand what is he doing, he will fail even with such simple inverted task. And understanding the algorithm for solving Diophantine equation is, of course, harder that memorizing the Euler function formula.

In addition we must say that this experiment wasn't pure enough, as the set of students was cut from the top: the most talented ones didn't have to pass this written exam, they had an exam in a project form instead.

\section{CONCLUSION}

The paper considers two approaches to the creation and use of constructive tasks related to the transfer of knowledge to a new situation.

One of the approaches is associated with the generation of non-standard tasks from typical by "reversion", that is, by turning the solution into conditions, and the conditions into a solution. A mass experiment on students who can solve a direct problem showed that most of them cannot solve the "reversed" tasks. This indicates not only that students could not cope with the transfer of knowledge to a new situation, but also that students viewed tasks in the narrow sense not as problems that need to be solved by any means, but as a task that needs to be solved by means of one of the templates outlined in the course. Thus, the transition to productive training requires not only a change in the content and form of presentation of educational tasks, but also in the structure of the learner's activity.

The second approach is connected with computer models, on the basis of which constructive tasks were set, requiring the transfer of knowledge to a new situation - instead of transforming formulas, it was necessary to create a construction that performed some transformations. It is shown that such an activity provides support for productive training and non-invasive monitoring of such training: the problem solutions themselves, presented in the form of freely created constructions, are a way of assessing the degree of understanding of the material because they include original ideas of the authors.

\section{References}

1. A. Watson and J. Mason, Mathematics as a Constructive Activity, London: Routledge, 2005.

2. E. C. Wittmann, "Mathematics Eduaction as a 'Design Science'," Educational Studies in Mathematics, vol. 29, pp. 355-374, 1995; doi: 10.1007/BF01273911 
3. E. Dubinsky, “Constructive Aspects of Reflective Abstraction in Advanced Mathematics," in Epistemiological Foundations of Mathematical Experience (Recent Research in Psychology), L. P. Steffe ed., New York: Springer, 1991, pp. 160-202; doi: 10.1007/978-1-4612-3178-3_9

4. J. B. Biggs, "Enhancing teaching through constructive alignment," Higher Education, vol. 32, no. 3, pp. 347-364, 1996; doi: 10.1007/BF00138871

5. S. N. Pozdniakov, I. A. Posov, A. V. Puhkov, and I. V. Tsvetova, "Science Popularization by Organizing Training Activities Within the Electronic Game Laboratories,” International Journal of Digital Literacy and Digital Competence, vol. 3, pp. 17-31, Jan.-Mar. 2012; doi: 10.4018/jdldc.2012010102

6. A. Maytarattanakon and I. A. Posov, "Avtomatizatsiya provedeniya distantsionnykh sorevnovanii, osnovannykh na issledovatel'skikh syuzhetakh po matematike i informatike [Automation of distance contests based on research problems in mathematics and informatics]," Computer Tools in Education, no. 6, pp. 45-51, 2014 (in Russian).

7. V. A. Akimushkin, S. N. Pozdniakov, and A. S. Chukhnov, "Constructive Problems in the Structure of the Olympiad in Discrete Mathematics and Theoretical Informatics," Olympiads in Informatics, vol. 11, pp. 3-18, 2017; doi: 10.15388/ioi.2017.01

Received 08.08.2019, The final version-11.09.2019.

Anton S. Chukhnov, lecturer of Department of Algorithmic Mathematics Saint Petersburg Electrotechnical University, septembreange@gmail.com

Компьютерные инструменты в образовании, 2019

№ 3: 96-104

УДК: $371.263:(373.62+004.9)$

http://cte.eltech.ru

doi:10.32603/2071-2340-2019-3-96-104

\section{Конструктивные задачи как средство «инвазивной» и «неинвазивной» оценки знаний}

Чухнов А. С. ${ }^{1}$, старший преподаватель, 凶 septembreange@gmail.com

${ }^{1}$ Санкт-Петербургский государственный электротехнический университет «ЛЭтИ» им. В. И. Ульянова (Ленина), ул. Профессора Попова, д. 5, корп. 3, 197376, Санкт-Петербург, Россия

\section{Аннотация}

Конструктивные задачи очень важны и встречаются в каждой области математики. Эта работа посвящена некоторым экспериментам с конструктивными задачами, которые проводились процессе обучения и во время экзамена.

Во-первых, некоторые конструктивные задания были даны студентам в рамках курса математической логики и теории алгоритмов в дистанционной форме. Задания были даны в качестве вспомогательного инструмента, и студенты не были обязаны их решать. Во-вторых, задания того же типа были даны более старшим студентам, которые проходили этот курс ранее. В ходе выполнения заданий их также просили протоколировать свою интеллектуальную деятельность.

Третий эксперимент был проведен во время письменного экзамена. Конструктивные задачи, которые были даны студентам на экзамене, выглядели как обратные к задачам, которые они решали в течение семестра. 
Ключевые слова: конструктивная задача, дистанционное обучение, неинвазивный мониторинг.

Цитирование: Чухнов А. С. Конструктивные задачи как средство «инвазивной» и «неинвазивной» оценки знаний // Компьютерные инструменты в образовании. 2019. № 3. C. 96-104. doi:10.32603/2071-2340-2019-3-96-104

Поступила в редакцию 08.08.2019, окончательный вариант - 11.09.2019.

Антон Сергеевич Чухнов, старший преподаватель кафедры алгоритмической математики СПбГэтУ «ЛЭТИ», 凶 septembreange@gmail.com 